\title{
Local Void Fractions and Bubble Velocity in Vertical Air-Water Two-Phase Flows Measured by Needle-Contact Capacitance Probe
}

\author{
Shanfang Huang $\left(\mathbb{D}^{1},{ }^{1}\right.$ Xiangxiang Wu, ${ }^{1}$ Benyang Zong, ${ }^{1}$ Yugao $\mathrm{Ma},{ }^{1}$ \\ Xiaoyu Guo, ${ }^{1}$ and Dong Wang ${ }^{2}$ \\ ${ }^{1}$ Department of Engineering Physics, Tsinghua University, Beijing 100084, China \\ ${ }^{2}$ State Key Laboratory of Multiphase Flow in Power Engineering, Xian Jiaotong University, Xian 710049, China
}

Correspondence should be addressed to Shanfang Huang; sfhuang@mail.tsinghua.edu.cn

Received 23 November 2017; Accepted 5 February 2018; Published 1 April 2018

Academic Editor: Stephen M. Bajorek

Copyright (c) 2018 Shanfang Huang et al. This is an open access article distributed under the Creative Commons Attribution License, which permits unrestricted use, distribution, and reproduction in any medium, provided the original work is properly cited.

\begin{abstract}
Multiphase flow measurements have become increasingly important in a wide range of industrial fields. In the present study, a dual needle-contact capacitance probe was newly designed to measure local void fractions and bubble velocity in a vertical channel, which was verified by digital high-speed camera system. The theoretical analyses and experiments show that the needle-contact capacitance probe can reliably measure void fractions with the readings almost independent of temperature and salinity for the experimental conditions. In addition, the trigger-level method was chosen as the signal processing method for the void fraction measurement, with a minimum relative error of $-4.59 \%$. The bubble velocity was accurately measured within a relative error of $10 \%$. Meanwhile, dynamic response of the dual needle-contact capacitance probe was analyzed in detail. The probe was then used to obtain raw signals for vertical pipe flow regimes, including plug flow, slug flow, churn flow, and bubbly flow. Further experiments indicate that the time series of the output signals vary as the different flow regimes and are consistent with each flow structure.
\end{abstract}

\section{Introduction}

Two-phase flows are encountered in many industrial processes, which have aroused much attention. Although extensive researches have been carried out on two-phase flow, a systematic understanding of the phase distribution is still lacking. This is mainly owing to the complexity of two-phase flow, the limitations of the available measurement techniques, and hence lack of reliable and extensive databases for twophase flows [1].

Several techniques have been developed to analyze phase distribution of multiphase flow, such as local probe method, gamma-ray attenuation method, chemical method, and ultrasound absorption method. Among these techniques, the use of needle-contact probes is a well-established method for the investigation of two-phase flows. Different measuring techniques have been employed for the needle-contact probes in the previous studies. Most sensors employ hot-film, optical, conductivity, and capacitance measurement techniques [2], but they have deficiencies to different extents regarding the measured substances.

Hot-film probes are applied to measure flow velocities, temperatures, and local void fractions by sensing the change in heat transfer. Many investigators have used the hot-film probe for two-phase flow measurements $[1,3,4]$. However, temperature drift and probe contamination often occur in hot-film probes, resulting in a significant shift in the calibration and a loss of sensitivity [5].

The optical probe $[6,7]$ made use of the difference in the reflection index between the phases for identification. Such probes adapt to varying flow conditions and are not affected by the fluid conductivity. However, the optical probe is enslaved to the transparency of the fluid, which restricts its implementation in industrial environments.

In terms of economics and convenience, conductance probe, which is based on the difference in electrical conductivities of mediums, has been widely used in many commercially available multiphase flow metering systems 


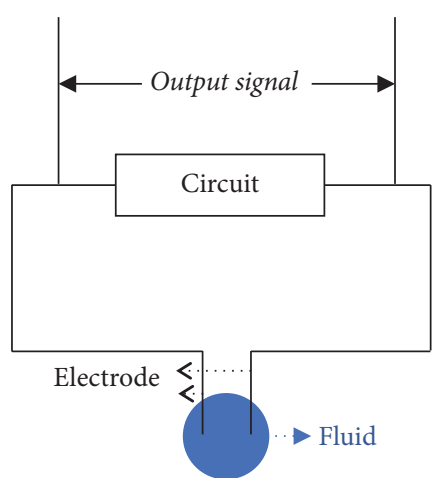

(a) Physical mechanism of needlecontact probe

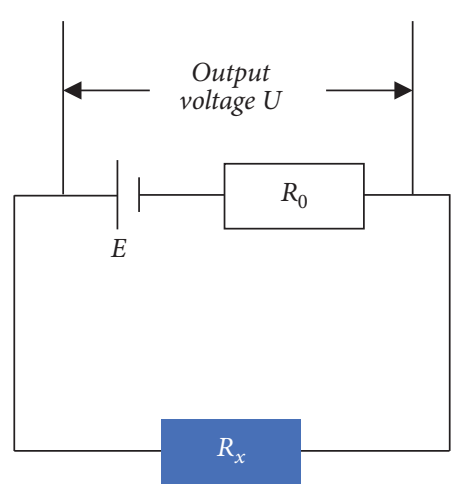

(b) Principle of traditional conductance probe

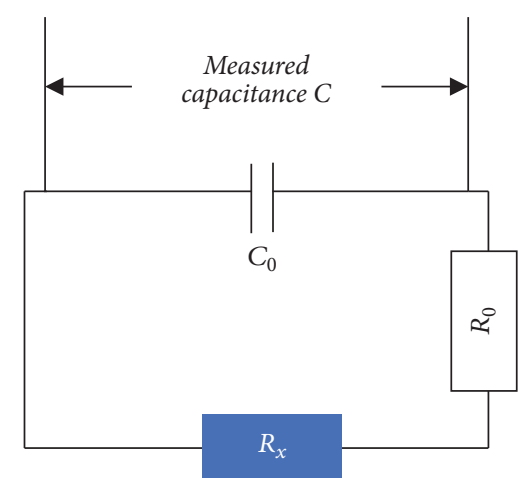

(c) Principle of present capacitance probe

FIGURE 1: Working principles of needle-contact electrical probes.

in the past few decades. Revankar and Ishii [8] measured the time-averaged local interfacial area concentration using a four-sensor resistivity probe. Prasser et al. [9] used an electrode-mesh tomograph for gas-liquid flows. Hibiki et al. [10] studied the characteristics of developing bubbly flows in a vertical mini pipe with a conductance probe. Conductance probes are reliable, sensitive, and of high speed. Moreover, this method can be used to measure void fractions not only in transparent pipes at low pressure, but also in metal pipes at high pressure. However, conductance probes can only identify multiphase mixtures where phase conductivities differ in several orders of magnitude [11]. In addition, the fluid salinity and temperature also directly affect the output signal.

Capacitance probe is another kind of electrical sensor. In the past twenty years, different capacitance sensor structures have been developed for two-phase flow research. Elkow and Rezkallah [12] used a capacitance probe to measure void fractions in gas-liquid flows. Netto et al. [13] studied the shapes of long bubbles in horizontal slug flow with a singlewire capacitance probe. Huang et al. [14] measured the water holdup in kerosene-water two-phase flows with a wire-mesh capacitance probe. Huang et al. [15] measured the equivalent water layer height in gas-liquid flows and identified the flow patterns using a single-wire capacitance probe. More recently, Huang et al. [16] used a high-speed camera and a single-wire capacitance probe to obtain flow pattern maps in hilly-terrain air-water-oil three-phase flows. Zhai et al. [17] measured the cross-correlation velocity of horizontal oil-water two-phase flows using parallel-wire capacitance probes. Capacitance probes have significant advantages in that they are almost independent of the liquid parameters and the electrode gap width.

Meanwhile, electrical needle sensors based on conductance and capacitance can also be subdivided depending on the number of electrodes [11]. Single-tip probes enable voidfraction measurements at the location of the tip. Doublesensor probes were further developed to measure the bubble velocities since the time delay between the signals of the two tips could be obtained. The double-sensor conductivity probe has been widely employed to investigate the distribution parameters in gas-liquid two-phase flow. Hibiki et al. [18] measured the local void fraction, interfacial area concentration, and interfacial velocity of vertical upward bubbly flows by a double-sensor conductivity probe. Zhao et al. [19] studied the local flow characteristics of oil-water dispersed flows in a vertical pipe using a double-sensor conductivity conductance probe. Zhao and Lucas [20] measured the local axial oil velocity and the local oil volume fraction with an array of dual-sensor conductance probes. Zhou et al. [21] measured the bubble dynamics in capillary two-phase flows by a micro double-tip conductivity probe. Therefore, doublesensor probes take the advantage of single-tip probes and can be used to obtain more flow parameters.

Thus, a new needle-contact capacitance probe, combining the advantages of the single-wire capacitance probe and the needle-contact probe, was proposed by Huang et al. [22] to measure the local void fraction and bubble velocity in gas-liquid two-phase flows. The probe was initially tested by Huang et al. [22], but its working principle has not been studied in depth.

To the new proposed needle-contact capacitance probe, the present study further analyses its working principle and provides more experimental data in vertical air-water twophase flows, including local void fraction and bubble velocity, as well as the time traces of different flow regimes. The present work is helpful to deeply understand the multiphase flow dynamics, as well as to provide reliable experimental data for numerical simulation.

\section{Working Principle of the Capacitance Probe}

Figure 1 shows a physical schematic of the needle-contact probe and a comparison of the working principles of the conductance/capacitance probes.

The measurement circuit for the needle-contact conductance/capacitance probe is either closed or open depending on whether the fluid is conductive or insulating. The phases are therefore identified.

For a traditional conductance probe, as shown in Figure $1(\mathrm{~b}), R_{x}$ is an equivalent resistance of the fluid between 
the electrodes of the probe, $R_{0}$ is a fixed resistor, and $E$ is an external power supply. For $R_{x}$

$$
R_{x}= \begin{cases}r & \text { when the tip is in water } \\ \infty & \text { when the tip is in air, }\end{cases}
$$

where $r$ should be a constant. The output signal, the voltage $U$, is expressed by

$$
U=\frac{E R_{x}}{R_{x}+R_{0}} .
$$

For practical applications, the equivalent resistance of water, $r$, can change dramatically as water conductance varies due to impurities or temperature. Therefore, low level signals when the probe is in water are unreliable.

For a practical needle-contact capacitance probe, the output signal of the circuit in Figure 1(c) can be expressed by

$$
C=\frac{C_{0}}{1+\left(\omega\left(R_{x}+R_{0}\right) C_{0}\right)^{2}},
$$

where the detection frequency $\omega$ is on the order of $1 \mathrm{kHz}$, the fixed resistance, $R_{0}$, is $10 \mathrm{k} \Omega$, and the constant capacitor, $C_{0}$, is less than $150 \mathrm{pF}$. When the probe is in water, $R_{x}$ equals $r$ and is less than $100 \mathrm{k} \Omega$. Then we can get

$$
10^{-10}<\left(\omega\left(r+R_{0}\right) C_{0}\right)^{2}<10^{-4} .
$$

Therefore, the output signal, $C$, is hardly influenced by the equivalent resistance $r$. Thus, this needle-contact capacitance probe overcomes the shortcoming of traditional conductance probe with stable low level outputs in water.

The following procedure of the needle-contact capacitance probe is very similar to that of the traditional needlecontact conductance probe. The output signal of the capacitance probe is then changed into a voltage and stored in a computer by a Capacitance/Voltage conversion (C/V) circuit

$$
U= \begin{cases}\text { high level, } & \text { when the tip is in air } \\ \text { low level, } & \text { when the tip is in water. }\end{cases}
$$

Figure 2 shows an ideal output profile over time when a group of bubbles pass over a needle-contact capacitance probe.

The local void fraction was determined by computing the ratio of the cumulated residence time of the sensor in the gas phase to the total measurement time, which was demonstrated by Angeli and Hewitt [23] and Zhao et al. [24]. The time-averaged void fraction can then be expressed by

$$
\alpha=\frac{t_{1}+t_{2}+\cdots+t_{n}}{t_{m}}
$$

where $t_{m}$ is the total sampling time and $t_{i}(i=1 \cdots n)$ is the time for each bubble to pass over the tip. The bubble velocity over a dual needle-contact probe can be found from the time lag between the two output signals as shown in Figure 3.

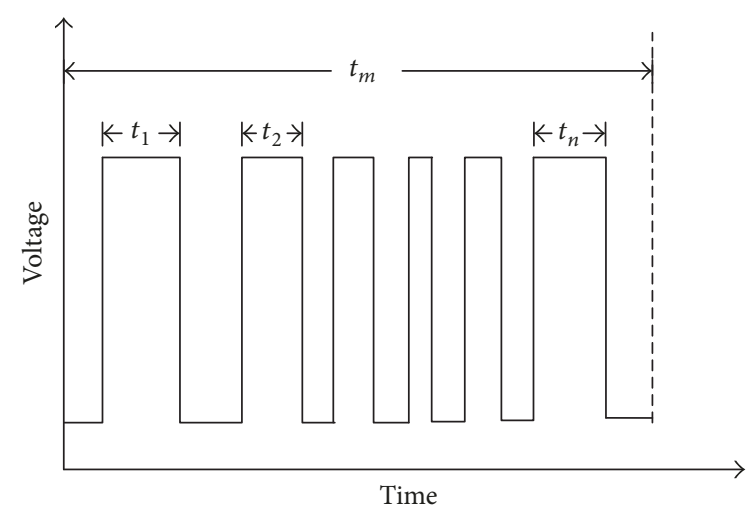

FIGURE 2: Ideal output voltage signals for a series of bubbles.

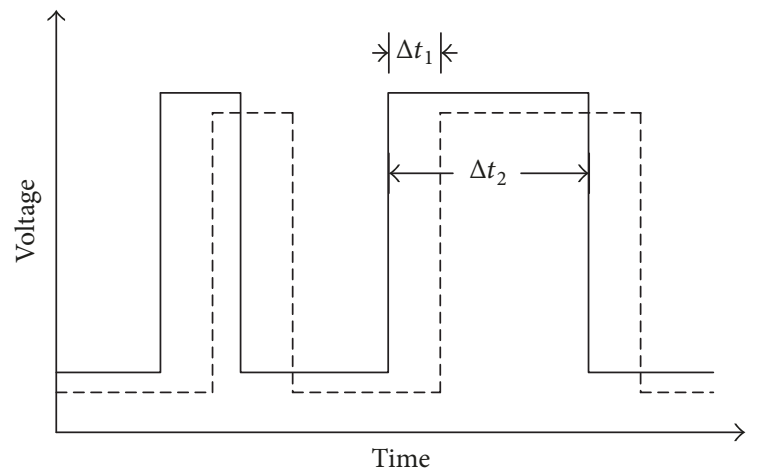

FIGURE 3: Time lag between the output signals of a double-tip probe.

The cross correlation method [21] is used to find the bubble velocity as

$$
v=\frac{L}{\Delta t_{1}},
$$

where $\Delta t_{1}$ is the time lag of the rising edge and $L$ is the distance between the two tips in the flow direction. Hence the bubble diameter is

$$
d=v \times \Delta t_{2}=\frac{L \Delta t_{2}}{\Delta t_{1}},
$$

where $\Delta t_{2}$ is the time difference between the rising and falling edges.

\section{Experimental Facility and Techniques}

3.1. Probe Verification Facility. The bubble detection performance was evaluated in the verification facility shown in Figure 4.

The Plexiglas vessel had a square cross-section with an inner side length of $50 \mathrm{~mm}$. Bubbles were injected into the water pool from the flat syringe needle fixed at the bottom of the vessel. The position of the syringe needle could be adjusted relative to the probe tip to make sure the center of the bubbles passing over the probe.

Three needles were used with inner diameters of $0.1 \mathrm{~mm}$, $0.5 \mathrm{~mm}$, and $0.9 \mathrm{~mm}$ to form different size bubbles. 50 discrete bubbles were injected into the pool from each needle. 


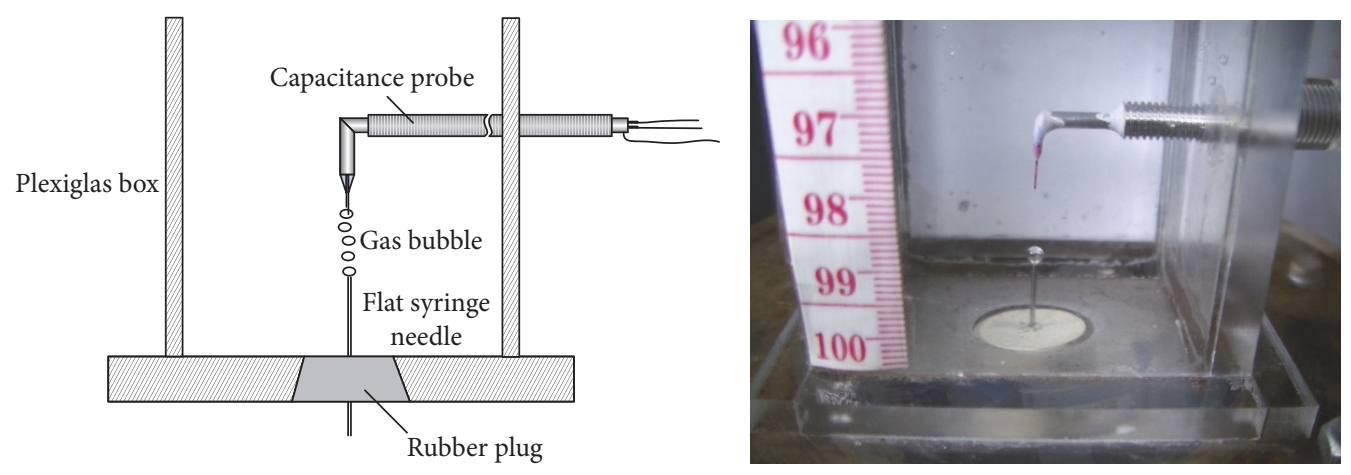

FIgURE 4: Probe verification facility.

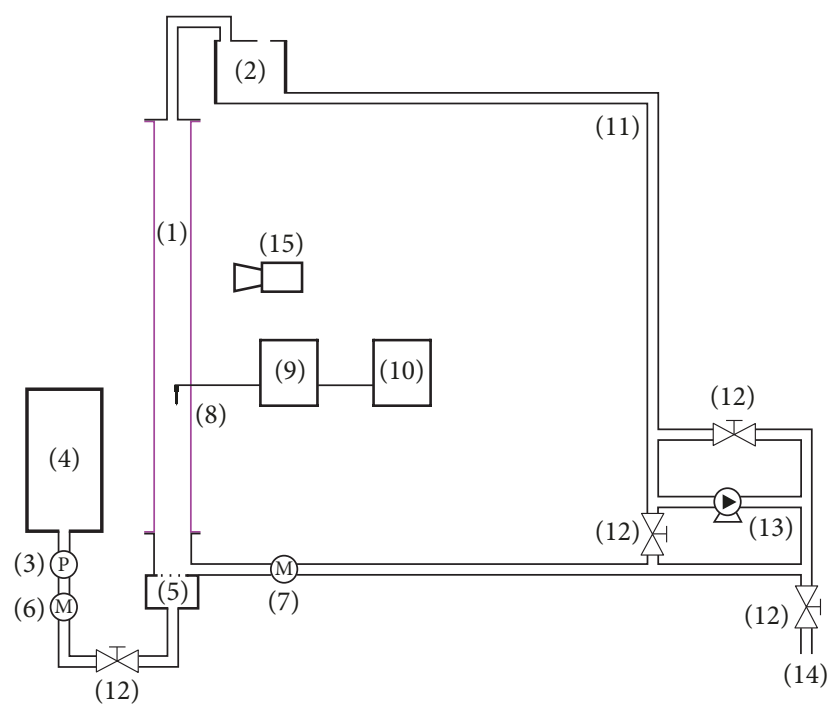

Figure 5: Air-water two-phase flow loop: (1) test section, (2) gasliquid separation tank, (3) pressure gauge, (4) air plenum, (5) two-phase mixing device, (6) gas flowmeter, (7) electromagnetic flowmeter, (8) dual needle-contact capacitance probe, (9) data acquisition system, (10) computer, (11) single-phase water pipe, (12) valve, (13) pump, (14) water inlet, and (15) high-speed video camera.

3.2. Flow Test Loop. Figure 5 shows the air-water two-phase flow loop. The loop could provide forced circulation or natural circulation by switching pump (13). Test section (1) was a square transparent Plexiglas vessel with a side width of $0.05 \mathrm{~m}$ and a length of $2 \mathrm{~m}$. The square cross section shown in Figure 6 reduces the flow structure deformation of the highspeed camera. The dual needle-contact capacitance probe (8) for the data acquisition system (9) was installed through the Plexiglas pipe. The pipe entrance (1) had a two-phase mixing device (5) while the pipe exit had a gas-liquid separation tank. The rest of the loop (11) was made of polypropylene random (PPR) pipes with an inner diameter of $50 \mathrm{~mm}$. The inlet air was pressurized by an air compressor and flowed into an air plenum (4). The air was injected into the loop through the air plenum (4) to keep a constant flowrate which was monitored by a rotameter (6) with an accuracy of $1 \%$. The air pressure was monitored by a pressure gauge (3) with an accuracy of
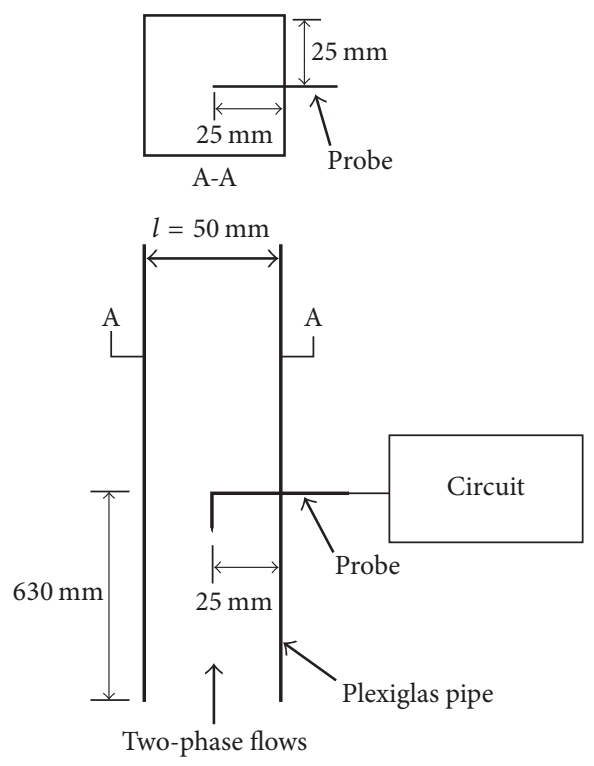

Figure 6: Test section.

$1 \%$. The water flowrate was monitored by an electromagnetic flowmeter (7) with an accuracy of $0.5 \%$.

The air was injected through a single $46 \mathrm{~mm}$ I.D. hole to produce plug, slug, and churn two-phase flows, while a honeycomb with $0.2 \mathrm{~mm}$ I.D. holes was used to produce bubbly two-phase flows.

The experiments were conducted at room temperature and atmospheric pressure. A little black ink was mixed into water so that the flow structure could be clearly seen. Therefore, the white parts in the photographs refer to gas while the rest refer to liquid. The superficial velocity of the air was $0.2 \sim 4.8 \mathrm{~m} / \mathrm{s}$ while that of the water was $0.008 \sim$ $0.08 \mathrm{~m} / \mathrm{s}$. The signal acquisition frequency was varied with the flow structure to balance the accuracy and efficiency with frequencies of 1 5 kHz. A high-speed video camera was used to record the flow structures at a frame rate of $1 \mathrm{kHz}$.

3.3. Test Section and Probe. The dual needle-contact capacitance probe was installed in the transparent Plexiglas square tube as shown in Figure 6. The probe was inserted perpendicular to the tube wall, where the tip is located at the center of 


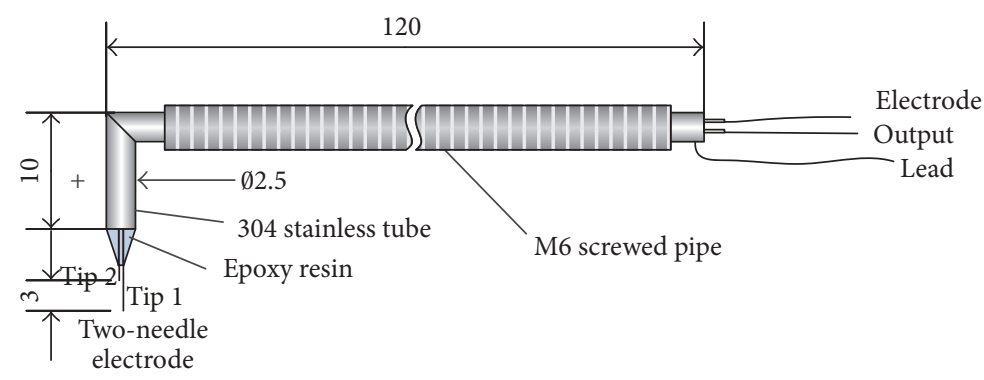

FIGURE 7: Schematic diagram of the capacitance probe.

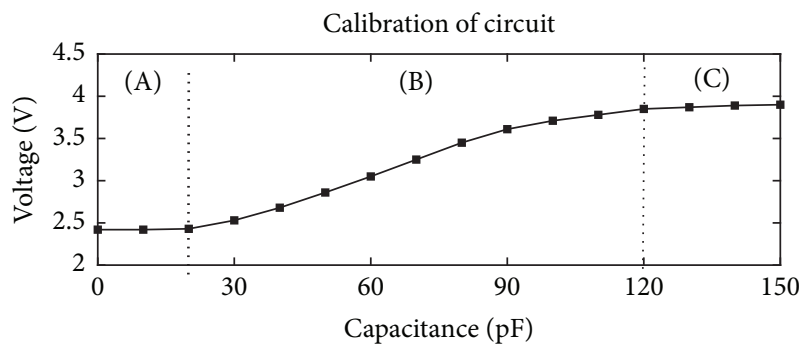

FIgURE 8: Circuit calibration with a fixed capacitor.

the cross section, $25 \mathrm{~mm}$ from the pipe wall. The capacitance probe structure shown in Figure 7 is similar to that of a traditional conductance probe [19].

3.4. C/V Conversion Circuit. The capacitance signals acquired by the probes were then converted to voltages through a $\mathrm{C} / \mathrm{V}$ conversion circuit based on the CAV444 integrated circuit. The output signal $V_{\text {out }}$ was [25]

$$
\begin{aligned}
V_{\mathrm{out}} & =V_{\mathrm{DIFF}}+V_{\mathrm{REF}} \\
& =\left(1+\frac{R_{1}}{R_{2}}\right) \frac{3 \cdot C_{\mathrm{M}} \cdot \Delta V_{\mathrm{CM}} \cdot R_{\mathrm{CM}}}{8 \cdot C_{\mathrm{W}} \cdot R_{\mathrm{CW}}}+V_{\mathrm{REF}} \cdot
\end{aligned}
$$

When the external voltage reference was set to $V_{\mathrm{REF}}=5 \mathrm{~V}$, the output signal was

$$
V_{\text {out }}=2.5+8.397 \times 10^{-3} \cdot C_{\mathrm{M}},
$$

where $C_{\mathrm{M}}$ is the measured capacitance, $\mathrm{pF}$.

A constant capacitor, $C_{0}$, was needed to make the probe work well. Figure 8 shows the calibration of the output as a function of the capacitance.

The calibration profile can be divided into parts $\mathrm{A}, \mathrm{B}$, and C. In part A $(0 \sim 30 \mathrm{pF})$, the output voltage is independent of the input capacitance with a stable output voltage of about $2.42 \mathrm{~V}$. In part B $(30 \sim 120 \mathrm{pF})$, the output voltage increases linearly with the capacitance. Part C $(120 \sim 150 \mathrm{pF})$ has a stable output voltage.

For this needle-contact capacitance probe, the fixed capacitance should be as high as possible to improve the robustness. On the other hand, it should be as low as possible to increase the sensitivity. As a compromise, the constant capacitance was set as $C_{0}=130 \mathrm{pF}$.

The output voltage signals from the circuit were recorded and stored into a computer through a NI USB-6218 data acquisition board, which is a bus-powered isolated USB $M$ Series multifunction data acquisition (DAQ) module optimized for a high accuracy at fast sampling rates [26].

3.5. Probe Calibration by Static Experiments. Static experiments were conducted to verify the needle-contact capacitance probe output. The capacitance probe consisted of two identical tips so the output signals were assumed to be the same. Unless stated otherwise, the signals reported in the following sections are from the front tip (tip 1) as shown in Figure 7.

The probe output from the static tests is shown in Figure 9 for liquid temperatures of $16 \sim 100^{\circ} \mathrm{C}$ and salinities up to $5 \%$. A larger salinity leads to a better conductivity of the water and thus to a higher accuracy, so no more tests of salinities exceeding 5\% were carried out. Further tests show that the output voltage variation is less than $1 \%$ for these conditions. Therefore, the dual needle-contact capacitance probe output is independent of the water temperature and the salinity in these ranges, which agrees well with the theoretical analysis in Section 2.

Static tests were also conducted to test the output signal response with a data acquisition frequency of $1 \mathrm{kHz}$. The probe was first put into air, then quickly inserted into water, and finally pulled back out into the air. The duration of each stage was $10 \mathrm{~s}$. Figure 10 shows the results.

Both theoretical analyses and experiments indicated that the dual needle-contact capacitance probe could reliably measure the two-phase flow parameters. Tests gave the high output voltage as $3.87 \mathrm{~V}$ and the low output voltage as $2.42 \mathrm{~V}$

$$
U= \begin{cases}3.87 \mathrm{~V}, & \text { when the tip is in air } \\ 2.42 \mathrm{~V}, & \text { when the tip is in water. }\end{cases}
$$

\section{Results and Discussion}

\subsection{Dynamic Response of the Dual Needle-Contact \\ Capacitance Probe}

4.1.1. Dynamic Response in Static Water Tests. A single bubble was injected into a static water pool through a $0.1 \mathrm{~mm}$ inner diameter syringe needle. Figure 11 shows the track of a single bubble against time. The time interval between consecutive bubbles was $0.02 \mathrm{~s}$. This image shows that the bubble immediately accelerates after being injected into 


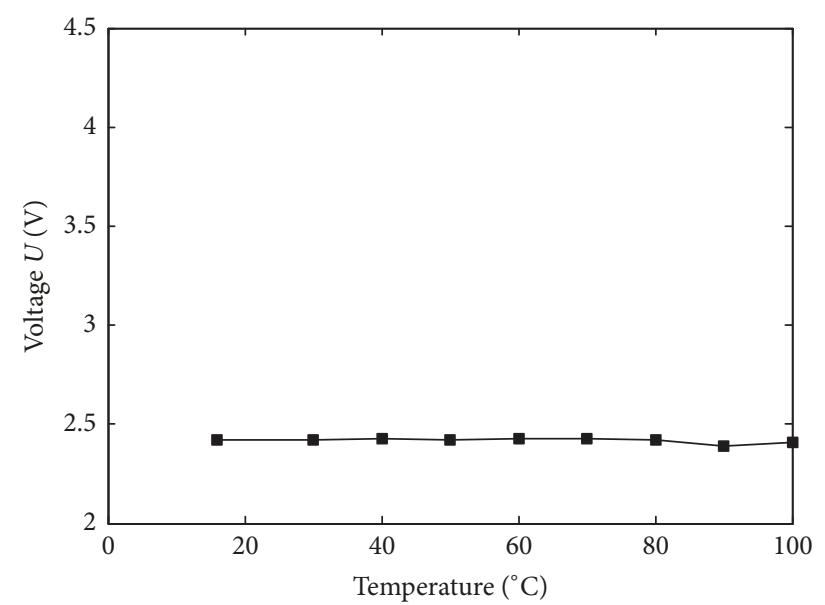

(a) Effect of water temperature

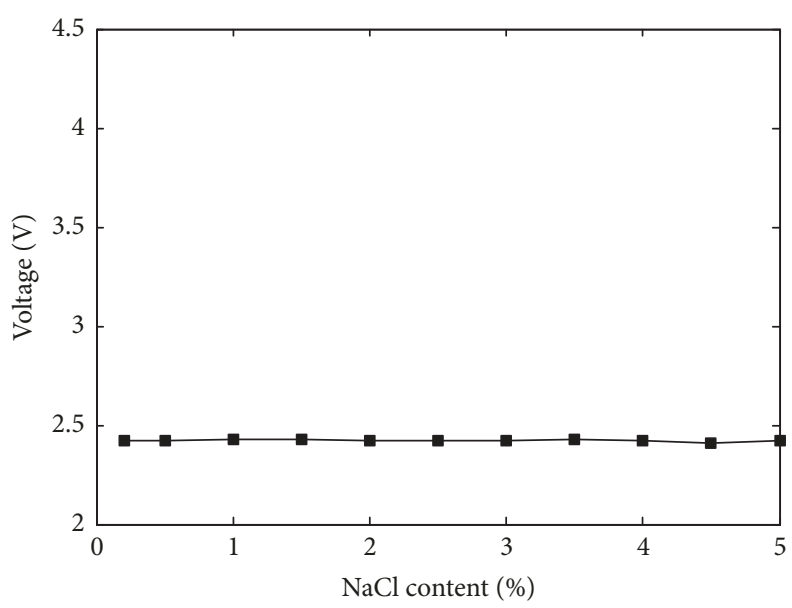

(b) Effect of water salinity

FIGURE 9: Effect of water properties on the probe output.

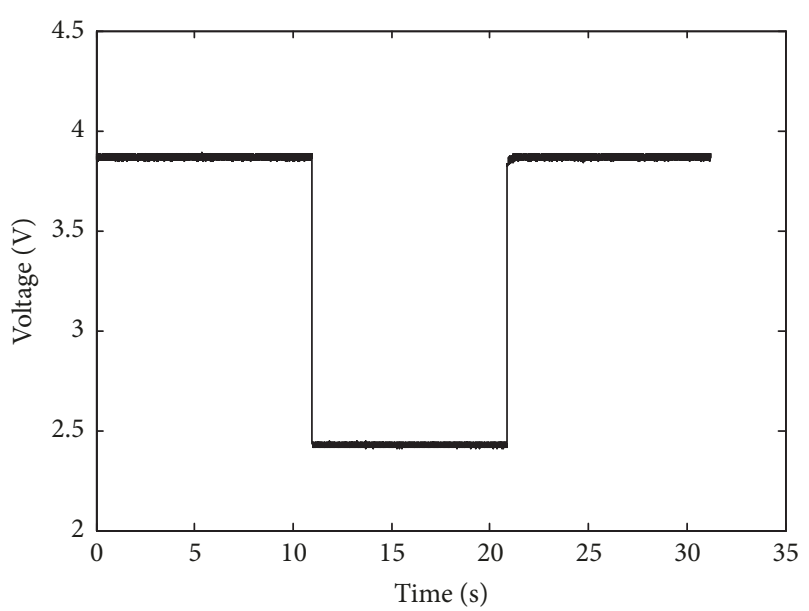

FIgURE 10: Output signals during the phase transitions.

the water and then decelerates after being punctured by the probe. After the bubble leaves the probe, it again accelerates.

The track and shape of each bubble were affected by the probe. The bubble-probe interaction included three stages: before contacting the probe tip, interacting with the probe tip, and leaving the probe tip. The void fraction measurements were mainly determined by the first two stages.

Figure 12 shows the images of the bubble shape as the bubble moved upwards before contacting with the probe. The bubble is initially spherical just after the bubble leaves the syringe tip. The bubble then flattens as it rises.

The interaction between the probe and the bubble shown in Figure 13 affects the probe output shown in Figure 14. The output voltage begins to increase once the probe contacts the bubble. Many factors affect the bubble dynamics and the probe output including the bubble diameter, the probe tip diameter, the air-water interface motion on the tip surface, and the bubble surface tension $[27,28]$. The upper surface of the bubble is pushed by the probe as shown in Figure 13(b). If

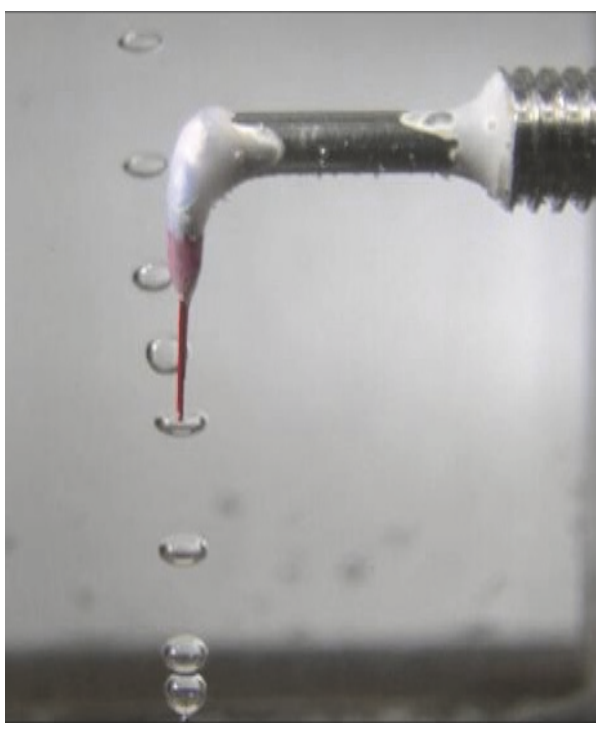

FIGURE 11: Interaction between the probe and the bubbles.

the bubble is small enough, it may be flattened by the probe. When the surface tension is not large enough to overcome the pressure, the upper surface will be punctured. The interface then deforms and changes the equivalent resistance, $R_{x}$, in (3), resulting in a change of the output voltage.

When the conductive tip of the probe pierces into the bubble as shown in Figure 13(c), the equivalent resistance, $R_{x}$, becomes essentially infinite. The output signal then approaches the maximum value in Figure 14(c).

When the probe tip contacts the lower surface of the bubble as shown in Figure 13(d), $R_{x}$ is then a constant and the output signal immediately returns to the low voltage. This process corresponds to stage (d) in Figure 14.

The lower surface of the bubble also bulges and is eventually punctured by the probe as shown in stages (e) and (f). 


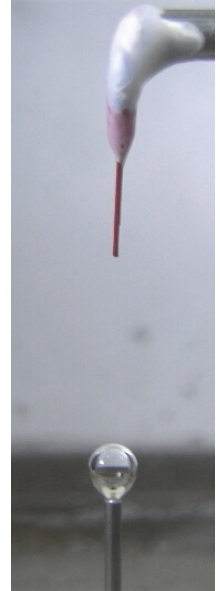

(a)

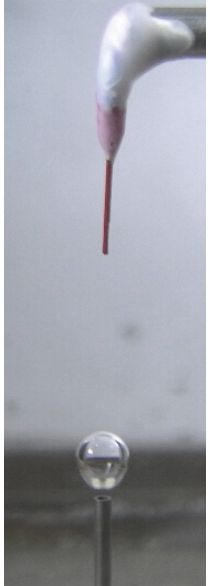

(b)

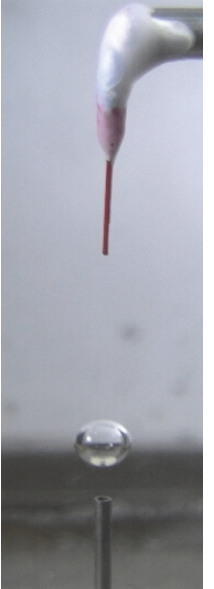

(c)

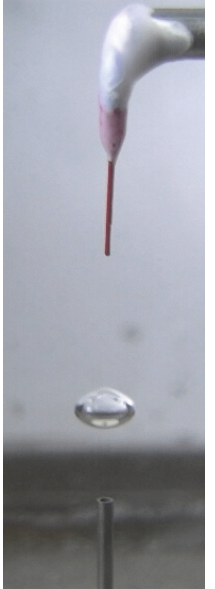

(d)

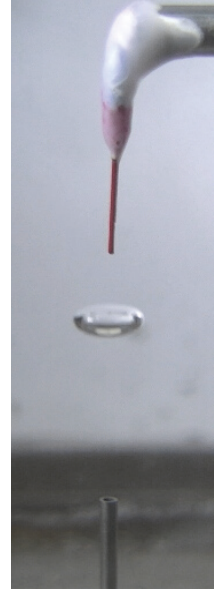

(e)

FIGURE 12: Images of the bubble shape before contacting the probe.
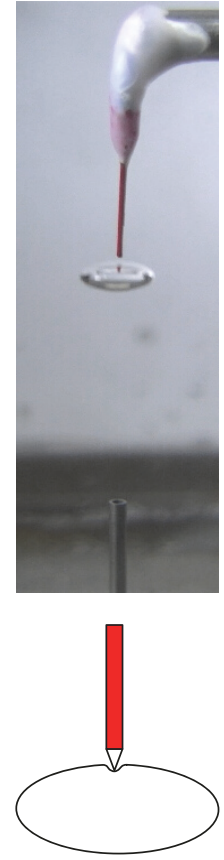

(a)
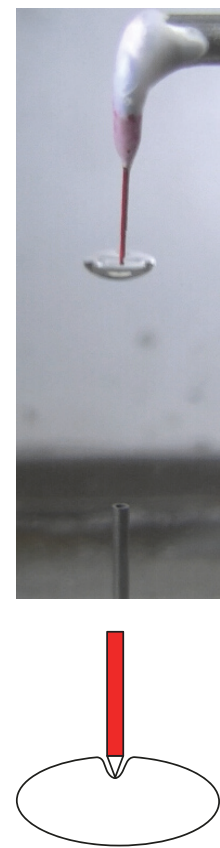

(b)
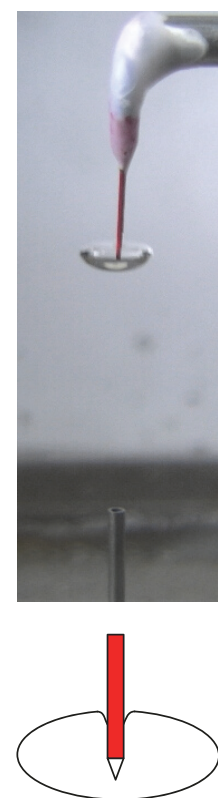

(c)
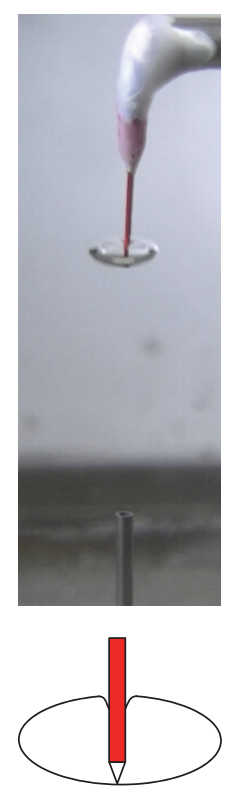

(d)
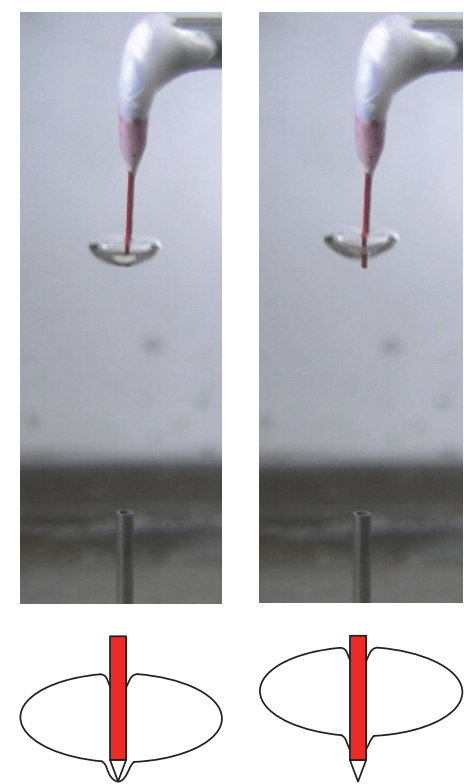

(e)

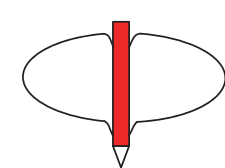

(f)

FIGURE 13: Bubble deformation when passing over the probe ( $0.1 \mathrm{~mm}$ inner diameter syringe).

Figure 14 shows the detailed physical interaction between the bubble and the probe including six steps corresponding to the probe output shown in Figure 15. This analysis of the needle-contact capacitance probe output is very similar to that of a needle-contact conductance probe [27].

4.1.2. Dynamic Response in Two-Phase Flows. In this section, the probe was tested in different flow patterns including single-phase flows, plug flows, bubbly slug flows, and churn flows in vertical tubes. The recording time for every case was $30 \mathrm{~s}$ except for the plug flow. Figure 15 shows the output signals and the corresponding flow structures. The air and water superficial velocities and the sampling frequency are listed in each case.

Case 1 (single-phase liquid $\left(\left\langle v_{g}\right\rangle=0 \mathrm{~m} / \mathrm{s},\left\langle v_{l}\right\rangle=0.05 \mathrm{~m} / \mathrm{s}\right.$, $f=1 \mathrm{kHz})$ ). The superficial velocity of the water in the vertical pipeline was kept at $\left\langle v_{l}\right\rangle=0.05 \mathrm{~m} / \mathrm{s}$. The probe tip was always in the water with a signal acquisition frequency of $1 \mathrm{kHz}$.

The output signal is constant at $2.42 \mathrm{~V}$, which agrees well with the flow structure recorded by the high-speed video camera. 
TABLE 1: Bubble velocities measured using the probe and the high-speed video.

\begin{tabular}{lcccc}
\hline $\begin{array}{l}\text { Syringe needle diameter } \\
(\mathrm{mm})\end{array}$ & $\begin{array}{c}\text { Bubble diameter } \\
(\mathrm{mm})\end{array}$ & $\begin{array}{c}V_{\mathrm{ncp}} \\
(\mathrm{mm} / \mathrm{s})\end{array}$ & $\begin{array}{c}V_{\mathrm{hsv}} \\
(\mathrm{mm} / \mathrm{s})\end{array}$ & Relative error $(\%)$ \\
\hline 0.1 & 1.3 & 272.7 & 250 & 9.09 \\
0.5 & 1.5 & 272.7 & 250 & 9.09 \\
0.9 & 1.6 & 253.5 & 250 & 1.41 \\
\hline
\end{tabular}

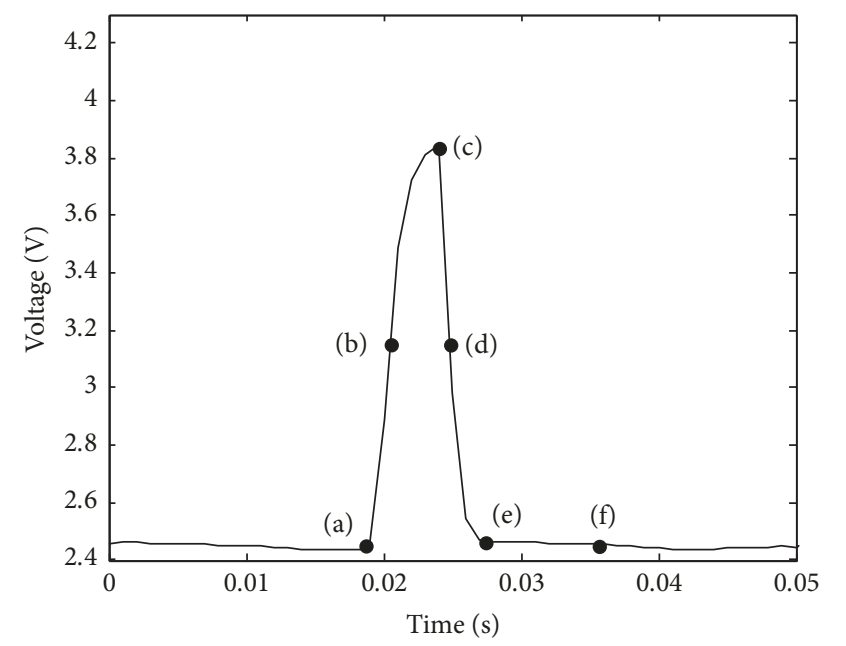

- Tip 1

FIGURE 14: Output signal of a needle-contact capacitance probe with a $0.1 \mathrm{~mm}$ inner diameter syringe.

Case 2 (single-phase gas $\left(\left\langle v_{g}\right\rangle=1.5 \mathrm{~m} / \mathrm{s},\left\langle v_{l}\right\rangle=0 \mathrm{~m} / \mathrm{s}\right.$, $f=1 \mathrm{kHz})$ ). As shown in Figure 15(b), the voltage signal is very stable with an average value of $U_{g}=3.87 \mathrm{~V}$.

Thus, Cases 1 and 2 show that the output voltage is independent of the fluid velocity.

Case 3 (bubbly flow $\left(\left\langle v_{g}\right\rangle=0.2 \mathrm{~m} / \mathrm{s},\left\langle v_{l}\right\rangle=0.008 \mathrm{~m} / \mathrm{s}\right.$, $f=1 \mathrm{kHz})$ ). A large number of small bubbles were dispersed into the water by the honeycomb plate as shown in Figure 15(c). Some of the small bubbles were not reflected in the output signals, indicating the disability of detecting small bubbles with this probe. This is mainly determined by the bubble diameter and velocity.

Case 4 (slug flow $(\langle v g\rangle=1.2 \mathrm{~m} / \mathrm{s},\langle v l\rangle=0.043 \mathrm{~m} / \mathrm{s}$, $f=2 \mathrm{kHz})$ ). Slug flow has a single long bubble with a smooth interface followed by some small bubbles as shown in Figure 15(d). The output signal shows the signal for 3 slugs with a nearly binary output when the big slug passes the tip.

Case 5 (churn flow $(\langle v g\rangle=4.8 \mathrm{~m} / \mathrm{s},\langle v l\rangle=0.086 \mathrm{~m} / \mathrm{s}$, $f=5 \mathrm{kHz})$ ). The air and water are randomly mixed with a wide range of bubble diameters as shown in Figure 15(e). The bubble motion is quite disordered, which is consistent with the output profile from the probe. The long periods with high voltages seen in the slug flow output are not observed in the churn flow output.

For slug and churn flows, the high-voltage output signals last for a long time due to the big bubbles. In bubbly flow, the output signal has many pulses due to large numbers of small bubbles. Thus, the probe output signals are quite different for different flow patterns and agree well with the corresponding flow structures. Thus, the dual needle-contact capacitance probe can reliably reflect the two-phase flow characteristics and can be used to measure two-phase flow parameters.

The measurement accuracy was qualitatively higher when the bubbles were larger and moved more slowly.

\subsection{Bubble Velocity Measurements}

4.2.1. Velocity Measurements for a Discrete Bubble. There is an axial distance between the two tips of $1.8 \mathrm{~mm}$ in the dual needle-contact probe. Figure 16 shows the time lag between the output signals of the probe when a bubble flowed over the two tips. Thus, the dual needle-contact capacitance probe signals can be used to calculate bubble velocities using cross correlation method [21].

A single bubble was injected into a static water pool through a $0.1 \mathrm{~mm}$ inner diameter flat-syringe needle with a time lag of $0.0066 \mathrm{~s}$ between the signals in Figure 16. The bubble velocity was then calculated $272.72 \mathrm{~mm} / \mathrm{s}$ according to (7). The high-speed video recorded the bubble velocity as $250 \mathrm{~mm} / \mathrm{s}$, so the probe measurement had a relative error of $9.09 \%$.

In the same way, the velocities of two other diameter bubbles injected through $0.5 \mathrm{~mm}$ and $0.9 \mathrm{~mm}$ inner diameter flat-syringe needles are shown in Table 1 , where $V_{\text {ncp }}$ is the velocity measured by the dual needle-contact capacitance probe and $V_{\mathrm{hsv}}$ is the velocity measured from the high-speed video.

As is shown in Table 1, the dual needle-contact capacitance probe can detect the velocities of $1.3 \sim 1.6 \mathrm{~mm}$ diameter bubbles with an error of less than $10 \%$ where the measurement accuracy increases with bubble diameter.

4.2.2. Velocity Measurements in Typical Two-Phase Flows. The axial distance between the two tips of the double-tip probe was again set to $3 \mathrm{~mm}$ to measure the bubble velocities in two-phase flows. Figure 17 shows the signals from the double-tip probe for different flow patterns.

In Figure 17(a), the time lag between the two signals for slug flow is $0.009 \mathrm{~s}$, so the bubble velocity in the plug flow was 

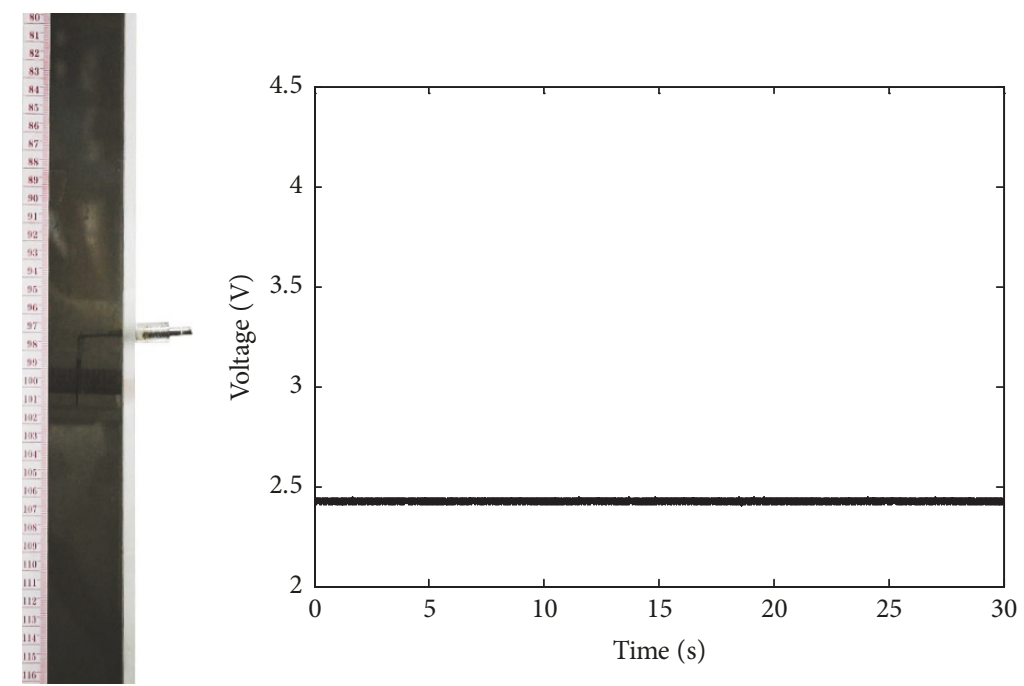

(a) Single-phase liquid $\left(\left\langle v_{g}\right\rangle=0 \mathrm{~m} / \mathrm{s},\left\langle v_{l}\right\rangle=0.05 \mathrm{~m} / \mathrm{s}\right)$
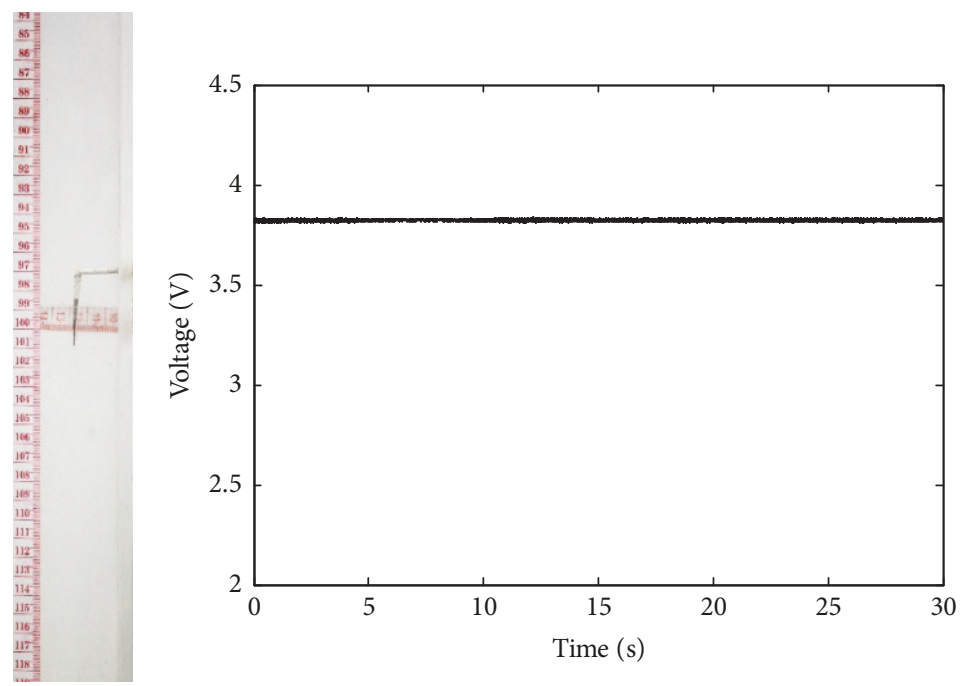

(b) Single-phase gas $\left(\left\langle v_{g}\right\rangle=1.5 \mathrm{~m} / \mathrm{s},\left\langle v_{l}\right\rangle=0 \mathrm{~m} / \mathrm{s}\right)$
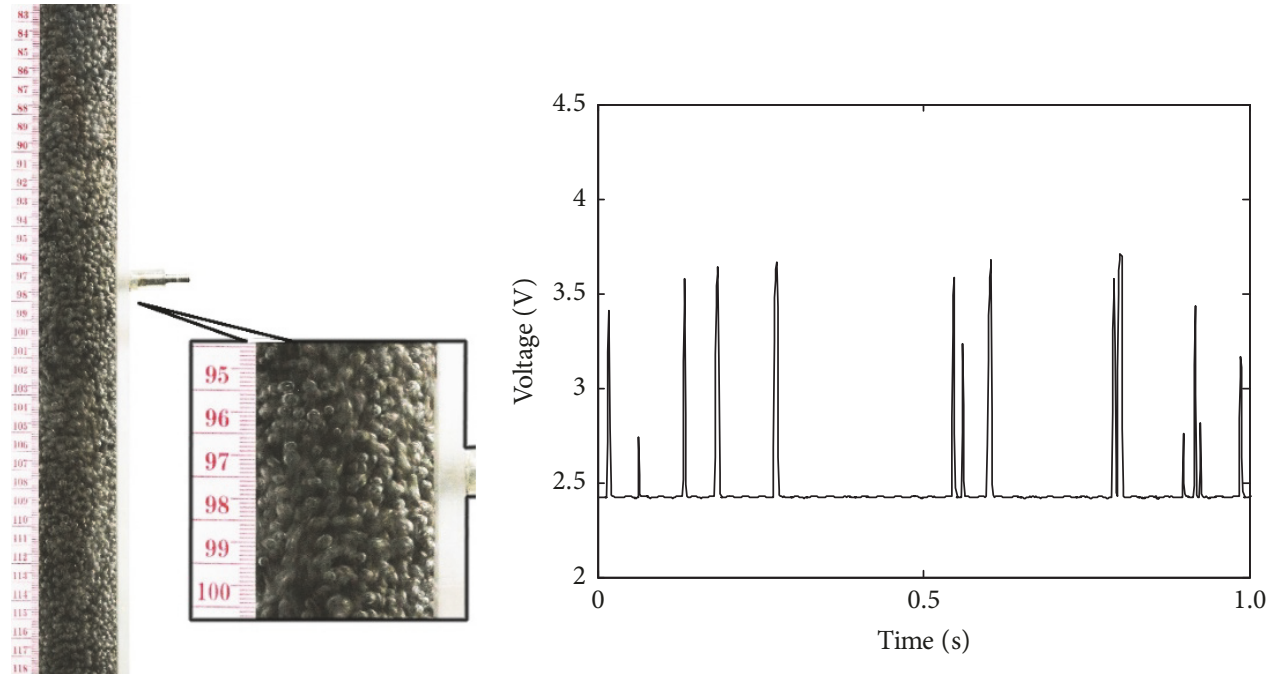

(c) Bubbly flow $\left(\left\langle v_{g}\right\rangle=0.2 \mathrm{~m} / \mathrm{s},\left\langle v_{l}\right\rangle=0.008 \mathrm{~m} / \mathrm{s}\right)$

Figure 15: Continued. 

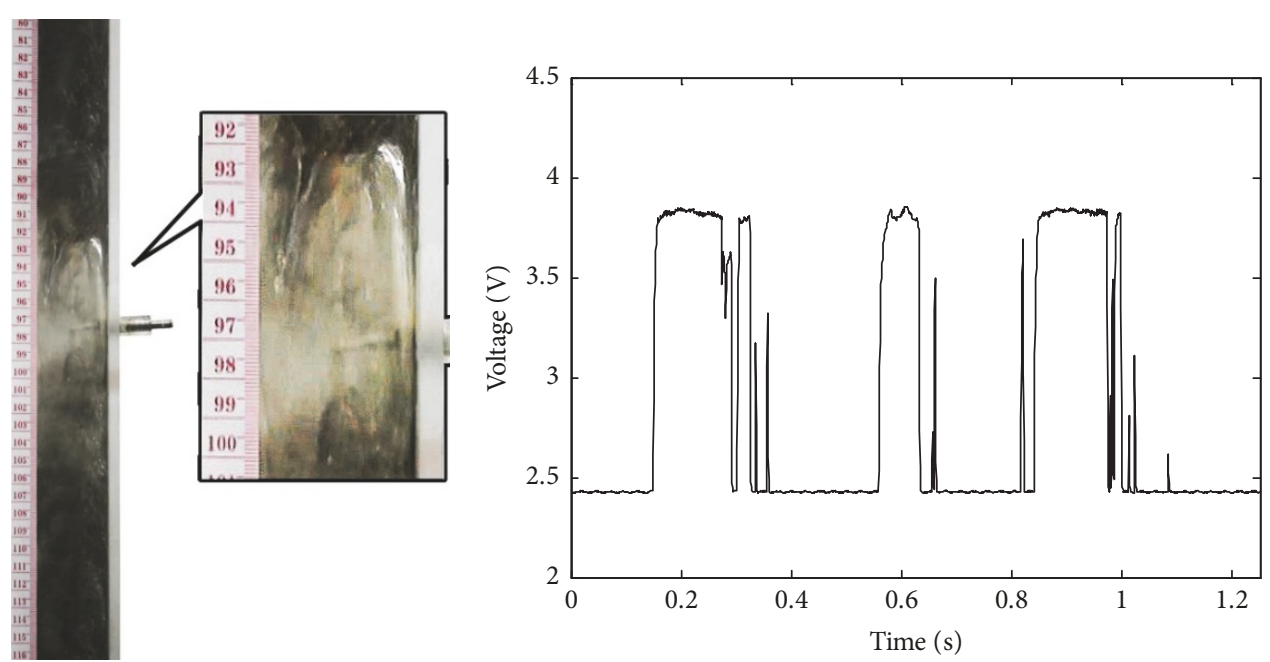

(d) Slug flow $\left(\left\langle v_{g}\right\rangle=1.2 \mathrm{~m} / \mathrm{s},\left\langle v_{l}\right\rangle=0.043 \mathrm{~m} / \mathrm{s}\right)$
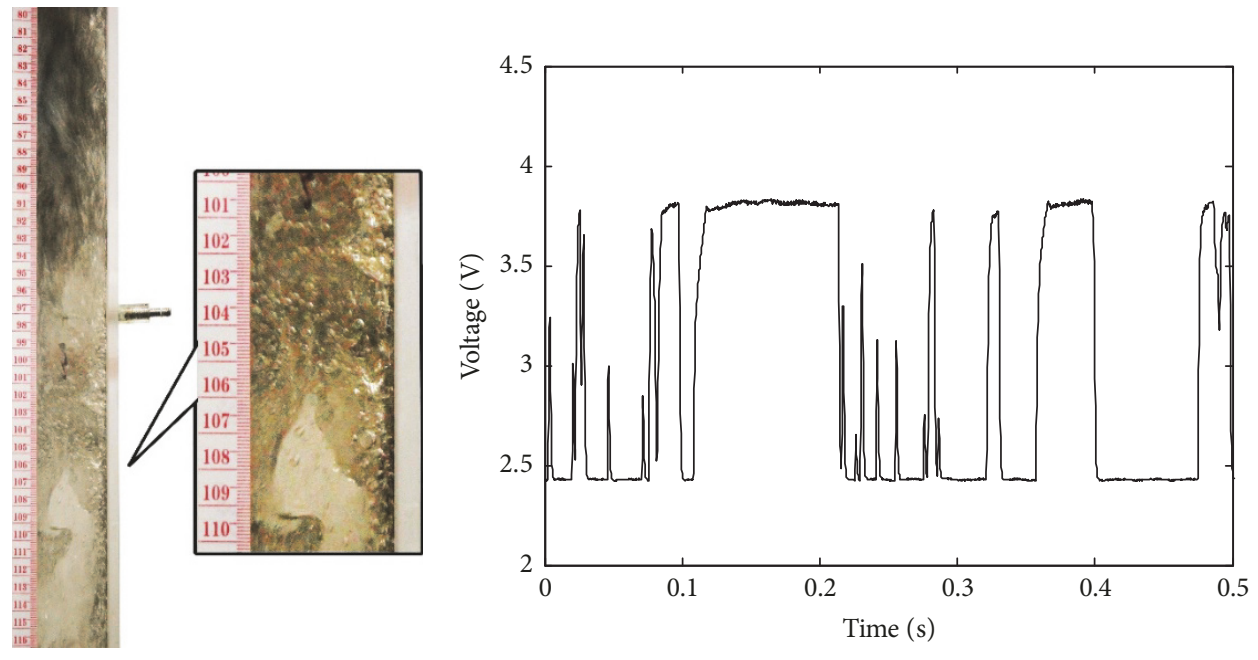

(e) Churn flow $\left(\left\langle v_{g}\right\rangle=4.8 \mathrm{~m} / \mathrm{s},\left\langle v_{l}\right\rangle=0.086 \mathrm{~m} / \mathrm{s}\right)$

FIGURE 15: Flow structures and output signals for different flow patterns.

$0.333 \mathrm{~m} / \mathrm{s}$ according to (7). The bubble velocity of bubbly flow, slug flow, and churn flow was $0.3750 .429 \mathrm{~m} / \mathrm{s}$, and $0.938 \mathrm{~m} / \mathrm{s}$, respectively.

The bubble velocity is closely related to the void wave speed when the bubble distribution is quite complicated.

\subsection{Void Fraction Measurements}

4.3.1. Data Processing Methods for Measuring the Void Fraction. The probe output signals for two-phase flows are binary in theory. However, for practical applications, the signal profiles are quite varied. The raw signals must be processed to determine the void fraction. Figure 18 shows a typical raw signal and the results of four traditional processing methods, including the threshold method, the slope method, the trigger-level method $[23,29]$, and the statistical method [30].

The flow pattern affects the output signal while the processing method affects the processing result. Thus, different signal processing methods may lead to different results.

The void fraction predicted by the threshold method is $33.6 \%$, by the slope method is $40.1 \%$, by the trigger-level method is $35.3 \%$, and by the statistical method is $32.3 \%$. The void fraction determined from the high speed video, similar to the method by Revankar and Ishii [31], is $\alpha=$ $37 \%$. The relative errors for the four methods are $-9.19 \%$, $8.38 \%,-4.59 \%$, and $-12.70 \%$, respectively. Since the triggerlevel method gave the best results for the current working conditions, it was used to process the following two-phase flow data.

4.3.2. Void Fraction in Typical Two-Phase Flows. Figure 19 shows the raw signals and the processed results for plug, bubbly, slug, and churn flow. The void fractions were calculated from (6).

The duration sum of the high voltage levels for bubbly flow, slug flow, and churn flow was $2.29 \mathrm{~s}, 9.33 \mathrm{~s}$, and $13.75 \mathrm{~s}$, 


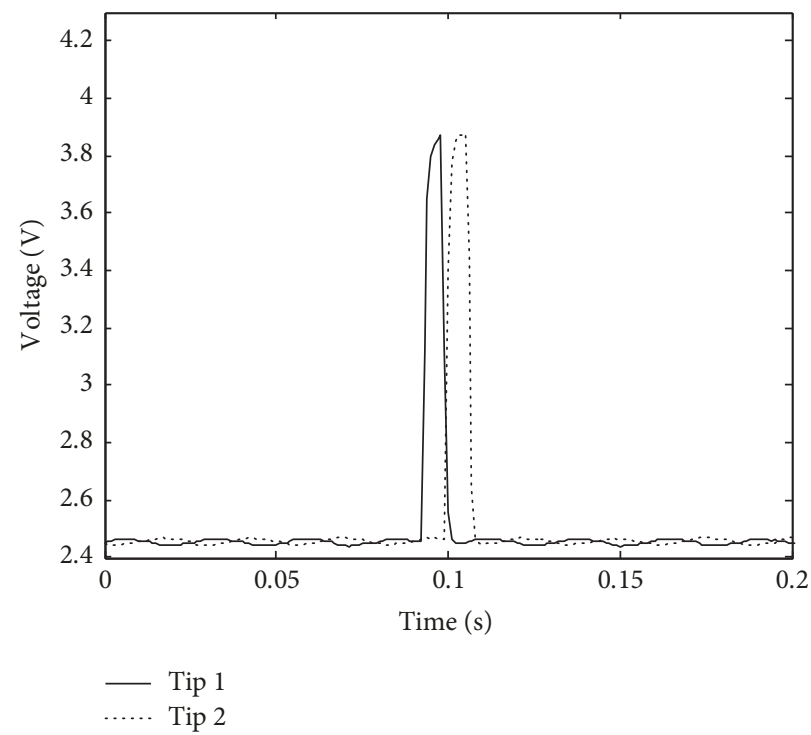

FIGURE 16: Time lag of the output signal for a single bubble.
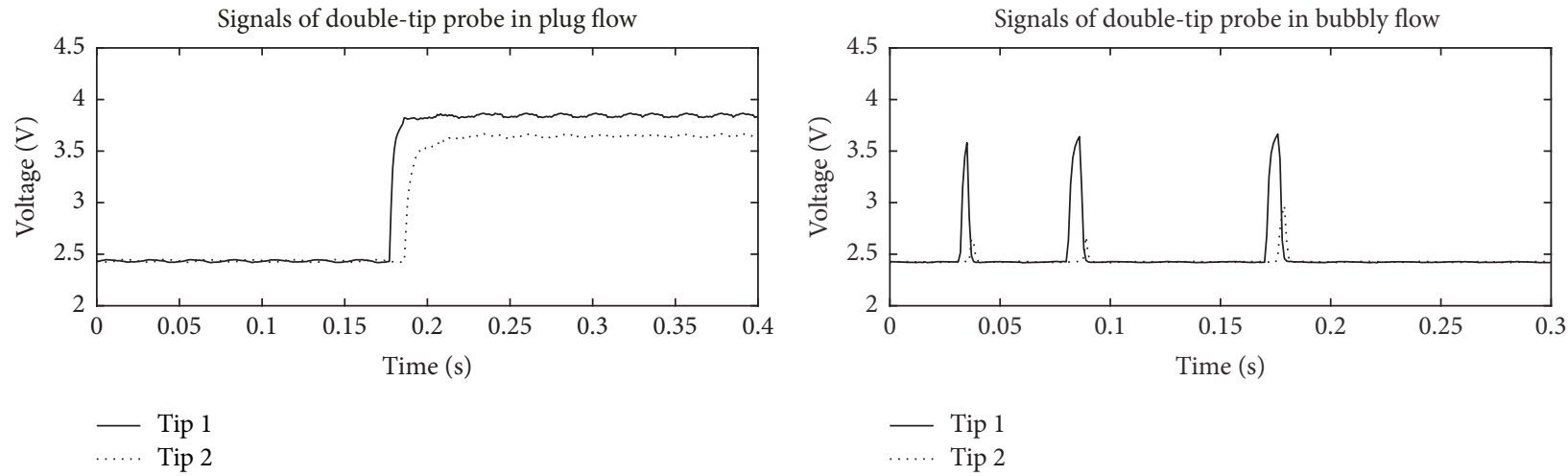

(a) Plug flow (a long bubble)

(b) Bubbly flow $\left(\left\langle v_{g}\right\rangle=0.2 \mathrm{~m} / \mathrm{s},\left\langle v_{l}\right\rangle=0.008 \mathrm{~m} / \mathrm{s}\right.$ )
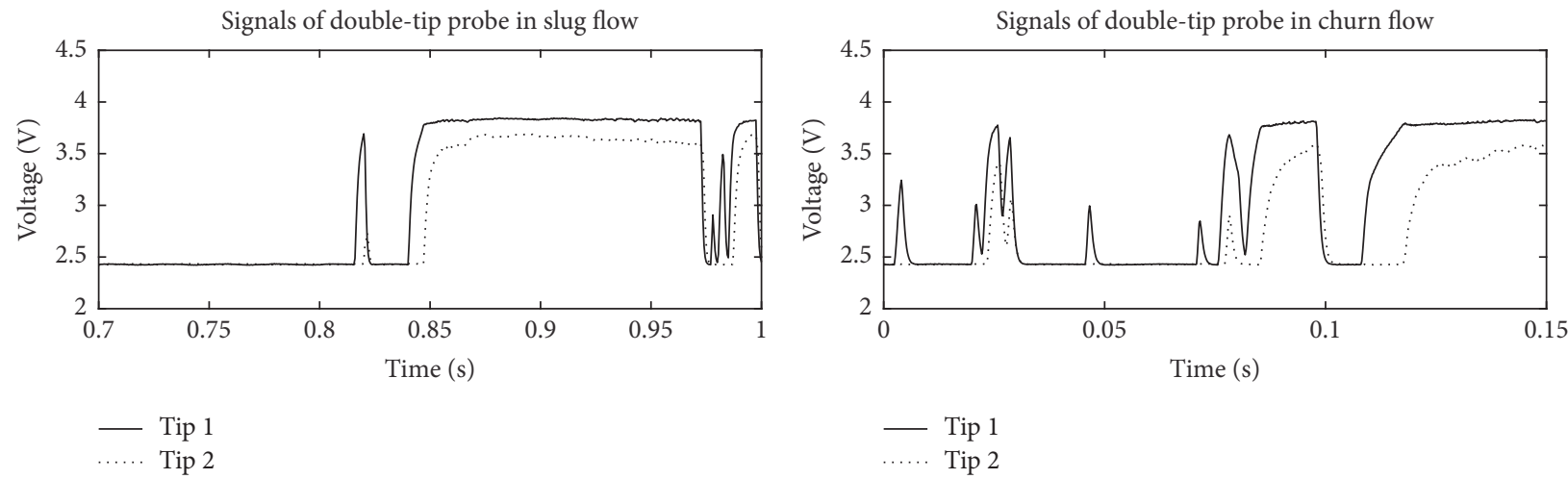

.... Tip 2

(c) Slug flow $\left(\left\langle v_{g}\right\rangle=1.2 \mathrm{~m} / \mathrm{s},\left\langle v_{l}\right\rangle=0.043 \mathrm{~m} / \mathrm{s}\right)$

(d) Churn flow $\left(\left\langle v_{g}\right\rangle=4.8 \mathrm{~m} / \mathrm{s},\left\langle v_{l}\right\rangle=0.086 \mathrm{~m} / \mathrm{s}\right)$

FIGURE 17: Double-tip signals for various flow patterns.

respectively, where the total measurement time was $30 \mathrm{~s}$ for each case. Therefore, the void fractions were $7.63 \%$ for bubbly flow, $31.1 \%$ for slug flow, and $45.8 \%$ for churn flow which is consistent with the visual flow structure observations.

\section{Conclusions}

A dual needle-contact capacitance was developed to measure the void fraction in gas-liquid two-phase flows, which is crucial for characterizing flow regime and multiphase flow 


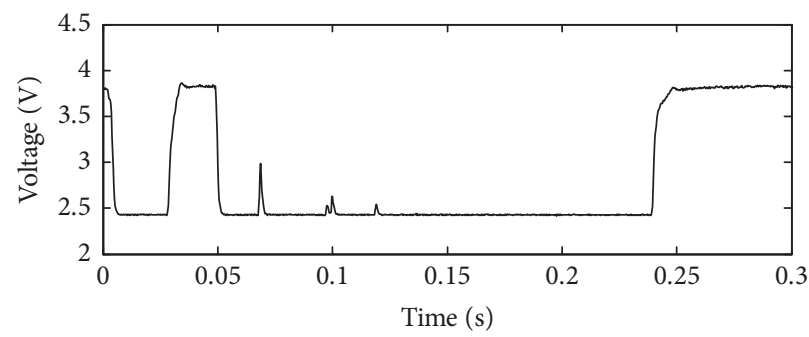

(a) Raw signal $\left(\left\langle v_{g}\right\rangle=2.0 \mathrm{~m} / \mathrm{s},\left\langle v_{l}\right\rangle=0.055 \mathrm{~m} / \mathrm{s}\right)$

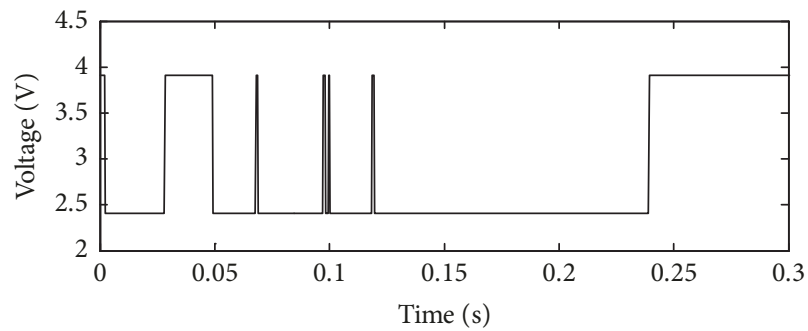

(c) Slope method

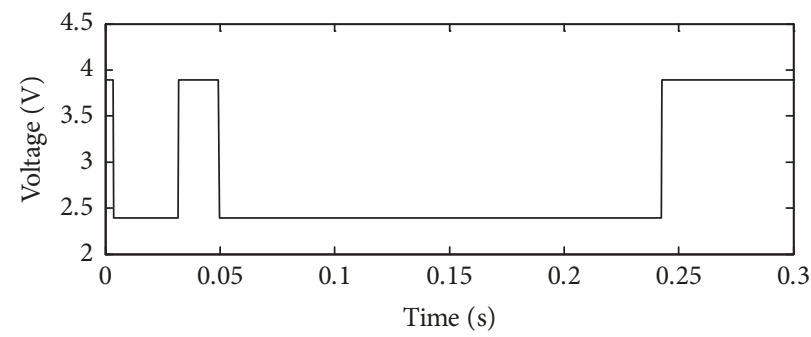

(b) Threshold method

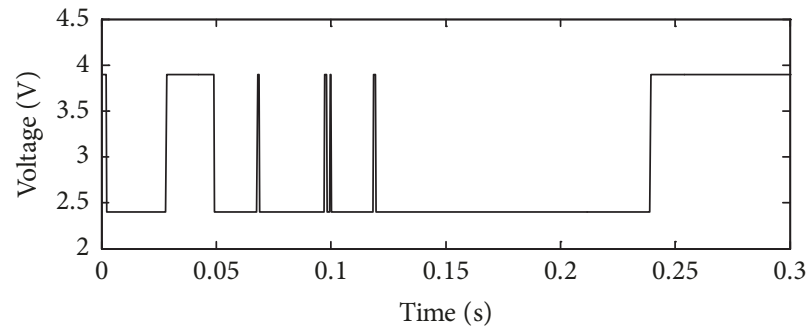

(d) Trigger-level method

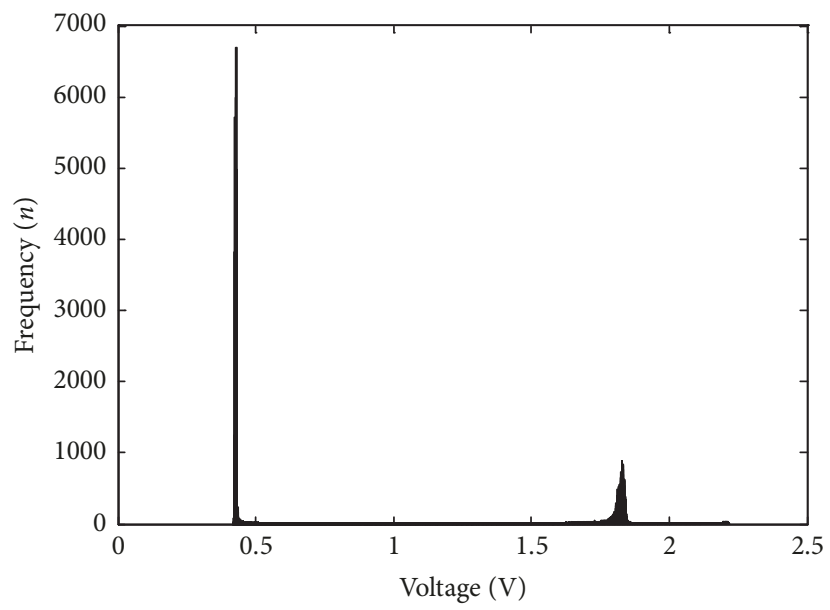

(e) Fourier transform frequency distribution (statistical method)

FIGURE 18: Raw signal and data processing results.

dynamics. The working principle of the dual needle-contact capacitance probe was based on the electrical conductivity difference between the two fluids. Comparing with a regular conductance probe, the dual needle-contact capacitance probe has an advantage of being independent of water electrical conductivity and temperature.

Two-phase flows experiments in plug, slug, and churn two-phase flows show that the probe output signals are consistent with the corresponding flow patterns for plug flow, slug flow, and churn flow.

For the typical flow conditions used in this study, the void fractions of the bubbly flow, slug flow, and churn flow were $7.63 \%, 31.1 \%$, and $45.8 \%$, respectively. This probe can also be used to measure bubble velocities in two-phase flows with relative errors of less than $10 \%$.

However, there are also some limitations of the probe. For instance, in the case of low void fraction measurement, the bubbles might be far less than $1 \mathrm{~mm}$ and behave like solid.
The probe will be invalid since the bubbles cannot penetrate the needle. Meanwhile, in high void fraction regions such as annular and churn turbulent regions, the flow dynamics is dominated by coalescence processes and the shapes of bubbles may become highly distorted [11]. Therefore, it is hard to calibrate using image processing and the dual needlecontact capacitance method may cause large errors.

\section{Conflicts of Interest}

The authors declare that there are no conflicts of interest regarding the publication of this paper.

\section{Acknowledgments}

The financial support provided by the Science and Technology on Reactor System Design Technology Laboratory, 

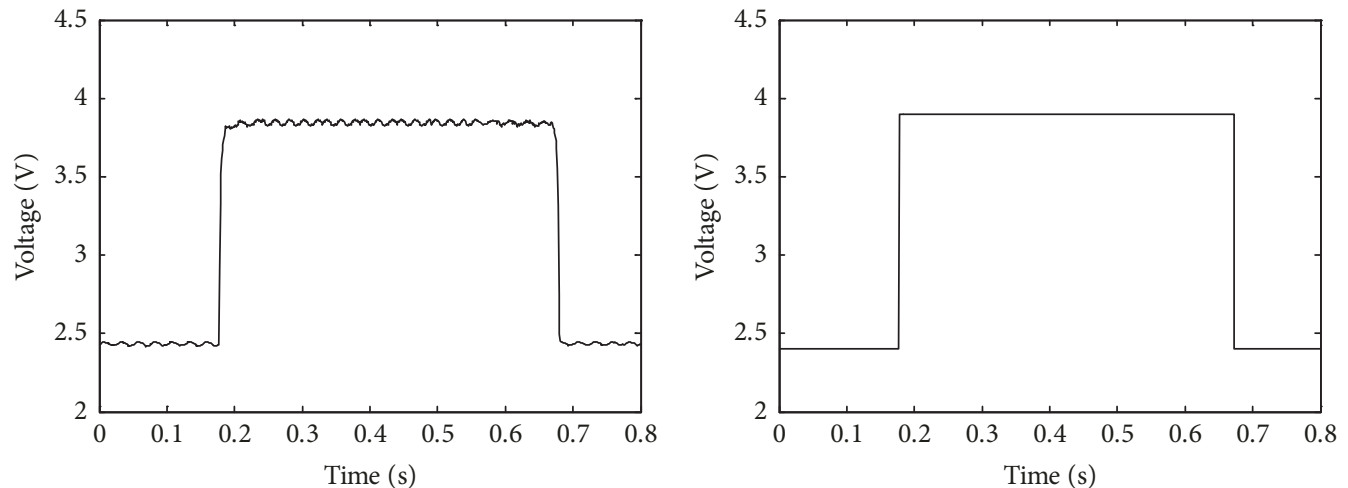

(a) Plug flow (a long bubble)
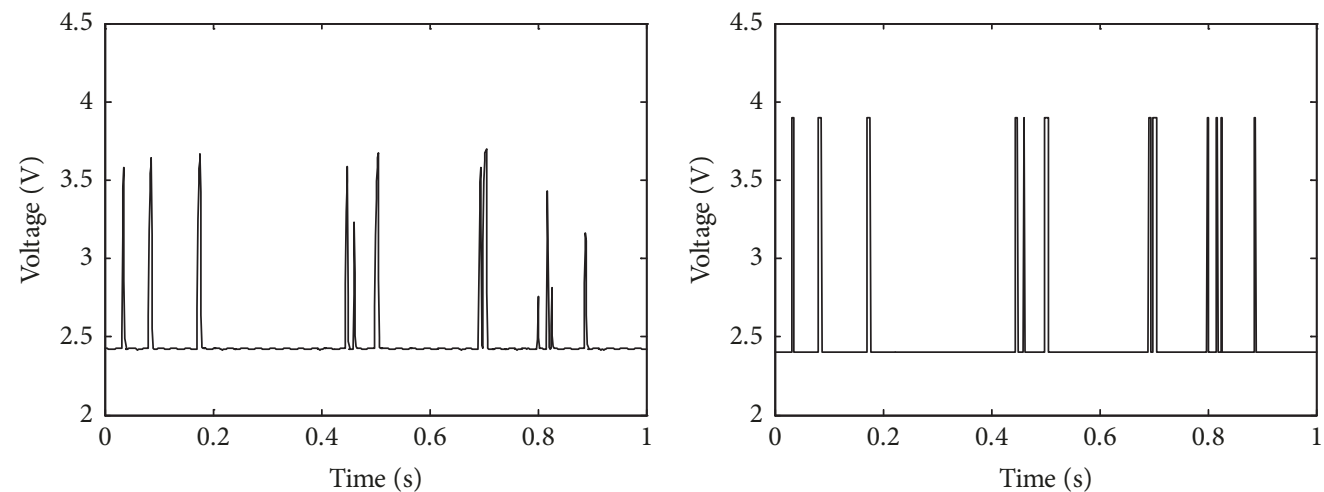

(b) Bubbly flow $\left(\left\langle v_{g}\right\rangle=0.2 \mathrm{~m} / \mathrm{s},\left\langle v_{l}\right\rangle=0.008 \mathrm{~m} / \mathrm{s}\right)$
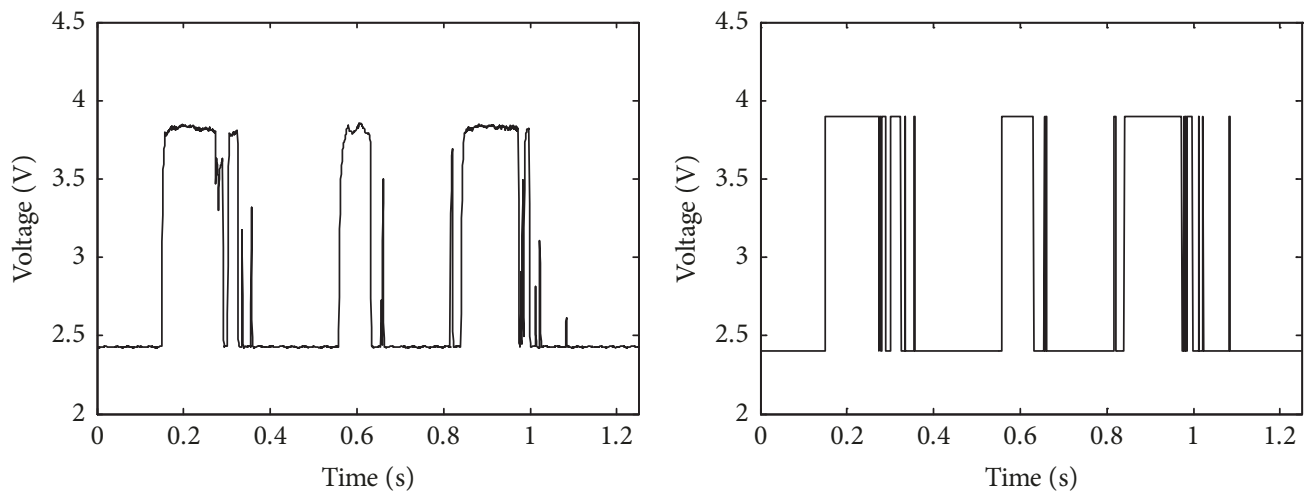

(c) Slug flow $\left(\left\langle v_{g}\right\rangle=1.2 \mathrm{~m} / \mathrm{s},\left\langle v_{l}\right\rangle=0.043 \mathrm{~m} / \mathrm{s}\right)$
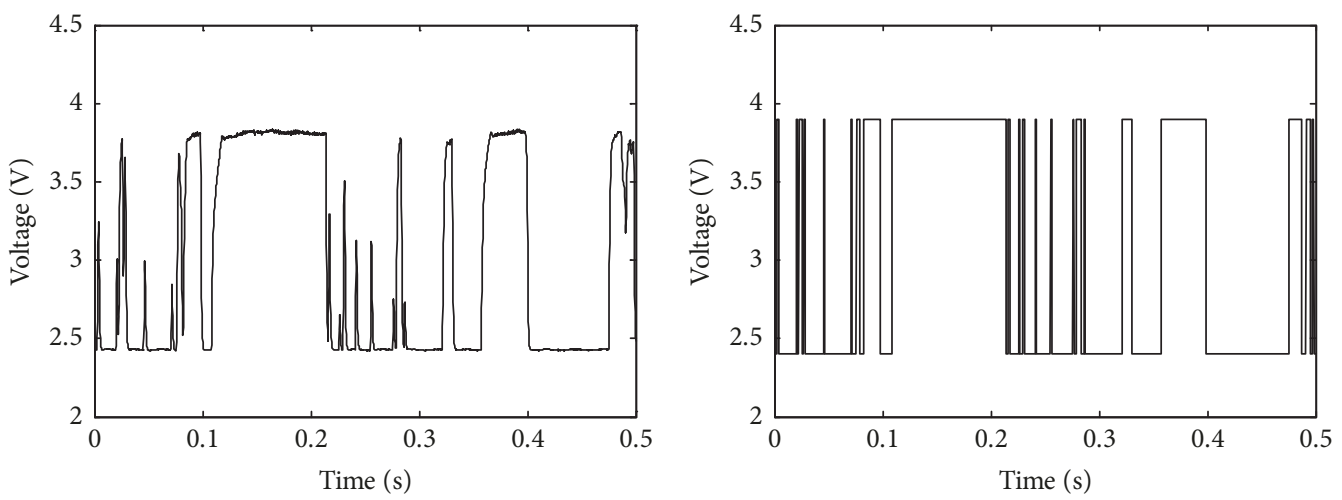

(d) Churn flow $\left(\left\langle v_{g}\right\rangle=4.8 \mathrm{~m} / \mathrm{s},\left\langle v_{l}\right\rangle=0.086 \mathrm{~m} / \mathrm{s}\right)$

FIGURE 19: Data processing results for typical two-phase flows. 
Nuclear Power Institute of China, and National Natural Science Foundation of China (51006068) is gratefully acknowledged.

\section{References}

[1] F. A. Hamad and S. He, "Evaluation of hot-film, dual optical and Pitot tube probes for liquid-liquid two-phase flow measurements," Flow Measurement and Instrumentation, vol. 21, no. 3, pp. 302-311, 2010.

[2] M. J. D. Silva, E. Schleicher, and U. Hampel, "A novel needle probe based on high-speed complex permittivity measurements for investigation of dynamic fluid flows," IEEE Transactions on Instrumentation \& Measurement, vol. 56, no. 4, pp. 1249-1256, 2007.

[3] B. Johansson, C. Ljus, and A. E. Almstedt, "Application of wedge-shaped hot-film probes in a gas-particle flow," Experimental Thermal \& Fluid Science, vol. 27, no. 2, pp. 187-191, 2003.

[4] H. Uchiyama and M. Ide, "Development of a hot-film anemometer calibrator for water flow measurement," Flow Measurement and Instrumentation, vol. 20, no. 2, pp. 75-80, 2009.

[5] H. H. Bruun, "Hot-film anemometry in liquid flows," Measurement Science and Technology, vol. 7, no. 10, pp. 1301-1312, 1996.

[6] R. T. Ramos, A. Holmes, X. Wu, and E. Dussan, "A local optical probe using fluorescence and reflectance for measurement of volume fractions in multi-phase flows," Measurement Science \& Technology, vol. 12, no. 7, p. 871, 2001.

[7] A. K. Jana, T. K. Mandal, D. P. Chakrabarti, G. Das, and P. K. Das, "An optical probe for liquid-liquid two-phase flows," Measurement Science \& Technology, vol. 18, no. 5, pp. 1563-1575, 2007.

[8] S. T. Revankar and M. Ishii, "Theory and measurement of local interfacial area using a four sensor probe in two-phase flow," International Journal of Heat \& Mass Transfer, vol. 36, no. 12, pp. 2997-3007, 1993.

[9] H. M. Prasser, A. Böttger, and J. Zschau, "A new electrodemesh tomograph for gas-liquid flows," Flow Measurement \& Instrumentation, vol. 9, no. 2, pp. 111-119, 1998.

[10] T. Hibiki, T. Hazuku, T. Takamasa, and M. Ishii, "Some characteristics of developing bubbly flow in a vertical mini pipe," International Journal of Heat and Fluid Flow, vol. 28, no. 5, pp. 1034-1048, 2007.

[11] G. Monrósandreu, R. Martinezcuenca, S. Torró, J. Escrig, B. Hewakandamby, and S. Chiva, "Multi-needle capacitance probe for non-conductive two-phase flows," Measurement Science \& Technology, vol. 27, no. 7, Article ID 074004, 2016.

[12] K. J. Elkow and K. S. Rezkallah, "Void fraction measurements in gas-liquid flows using capacitance sensors," International Journal of Multiphase Flow, vol. 23, no. 8, pp. 1153-1163, 1996.

[13] J. R. F. Netto, J. Fabre, and L. Peresson, "Shape of long bubbles in horizontal slug flow," International Journal of Multiphase Flow, vol. 25, no. 6, pp. 1129-1160, 1999.

[14] S. Huang, X. Zhang, D. Wang, and Z. Lin, "Water holdup measurement in kerosene water two-phase flows," Measurement Science \& Technology, vol. 18, no. 12, p. 3784, 2007.

[15] S. Huang, X. Zhang, D. Wang, and Z. Lin, "Equivalent water layer height $(\mathrm{EWLH})$ measurement by a single-wire capacitance probe in gas-liquid flows," International Journal of Multiphase Flow, vol. 34, no. 9, pp. 809-818, 2008.
[16] S. Huang, B. Zhang, J. Lu, and D. Wang, "Study on flow pattern maps in hilly-terrain air-water-oil three-phase flows," Experimental Thermal \& Fluid Science, vol. 47, no. 5, pp. 158171, 2013.

[17] L. Zhai, N. Jin, Z. Gao, A. Zhao, and L. Zhu, "Cross-correlation velocity measurement of horizontal oil-water two-phase flow by using parallel-wire capacitance probe," Experimental Thermal \& Fluid Science, vol. 53, no. 2, pp. 277-289, 2014.

[18] T. Hibiki, S. Rong, Y. Mi et al., "Experimental study on interfacial area transport in vertical upward bubbly two-phase flow in an annulus," International Journal of Heat \& Mass Transfer, vol. 46, no. 3, pp. 427-441, 2003.

[19] D. Zhao, L. Guo, X. Hu, X. Zhang, and X. Wang, "Experimental study on local characteristics of oil-water dispersed flow in a vertical pipe," International Journal of Multiphase Flow, vol. 32, no. 10, pp. 1254-1268, 2006.

[20] X. Zhao and G. P. Lucas, "Use of a novel dual-sensor probe array and electrical resistance tomography for characterization of the mean and time-dependent properties of inclined, bubbly oil-inwater pipe flows," Measurement Science \& Technology, vol. 22, no. 22, Article ID 104012, 2011.

[21] Y. Zhou, Q. Zhang, H. Liu, and Z. Lei, "Measurements and characterization of bubble dynamics in capillary two-phase flows by a micro double-tip conductivity probe," Flow Measurement \& Instrumentation, vol. 24, no. 2, pp. 36-42, 2012.

[22] S. Huang, J. Lu, B. Zhang, and D. Wang, "Phase identification by a novel needle-contact capacitance probe in gas-liquid twophase flows," Nuclear Science and Techniques, vol. 21, no. 5, pp. 316-320, 2010.

[23] P. Angeli and G. F. Hewitt, "Flow structure in horizontal oilwater flow," International Journal of Multiphase Flow, vol. 26, no. 7, pp. 1117-1140, 2000.

[24] D. Zhao, L. Guo, C. Lin, and X. Zhang, "An experimental study on local interfacial area concentration using a double-sensor probe," International Journal of Heat \& Mass Transfer, vol. 48, no. 10, pp. 1926-1935, 2005.

[25] "CAV444 Linear C/V-Converter for capacitive input signals," http://www.analogmicro.de, 2014.

[26] “NI USB-6218," http://www.ni.com, 2010.

[27] P. Gherson and P. S. Lykoudis, "Local measurements in twophase liquid-metal magneto-fluid-mechanic flow," Journal of Fluid Mechanics, vol. 147, pp. 81-104, 1984.

[28] H. Toral, "A study of the hot-wire anemometer for measuring void fraction in two phase flow," Journal of Physics E Scientific Instruments, vol. 14, no. 7, p. 822, 1981.

[29] R. V. D. Welle, "Void fraction, bubble velocity and bubble size in two-phase flow," International Journal of Multiphase Flow, vol. 11, no. 3, pp. 317-345, 1985.

[30] J. M. Delhaye, "Hot-film anemometry in two-phase flow," in proceedings of the Eleventh Nat. ASME/AICHE Heat Transfer Conference, pp. 58-69, Minneapolis, MN, USA, 1969.

[31] S. T. Revankar and M. Ishii, "Local interfacial area measurement in bubbly flow," International Journal of Heat \& Mass Transfer, vol. 35, no. 4, pp. 913-925, 1992. 

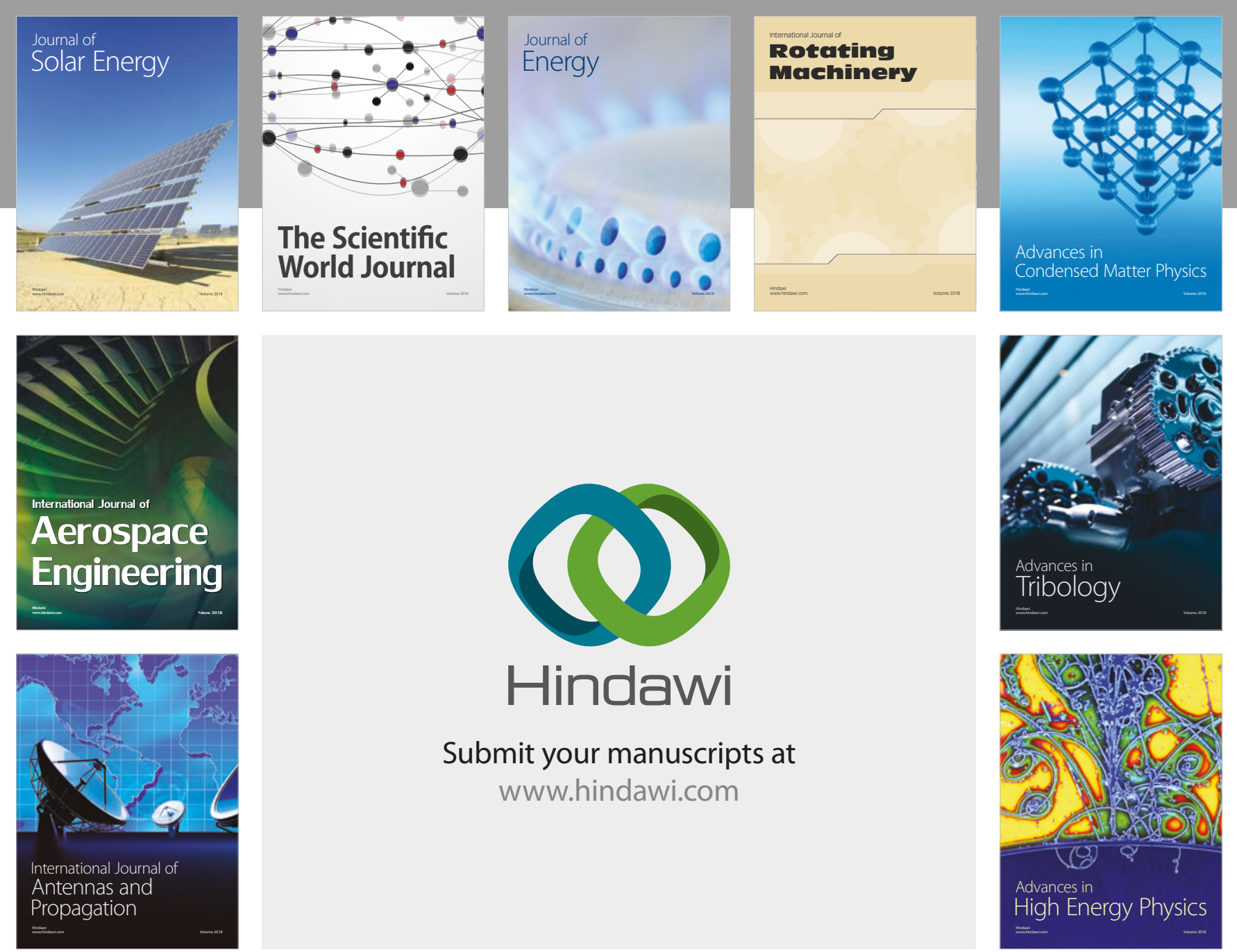

Submit your manuscripts at

www.hindawi.com
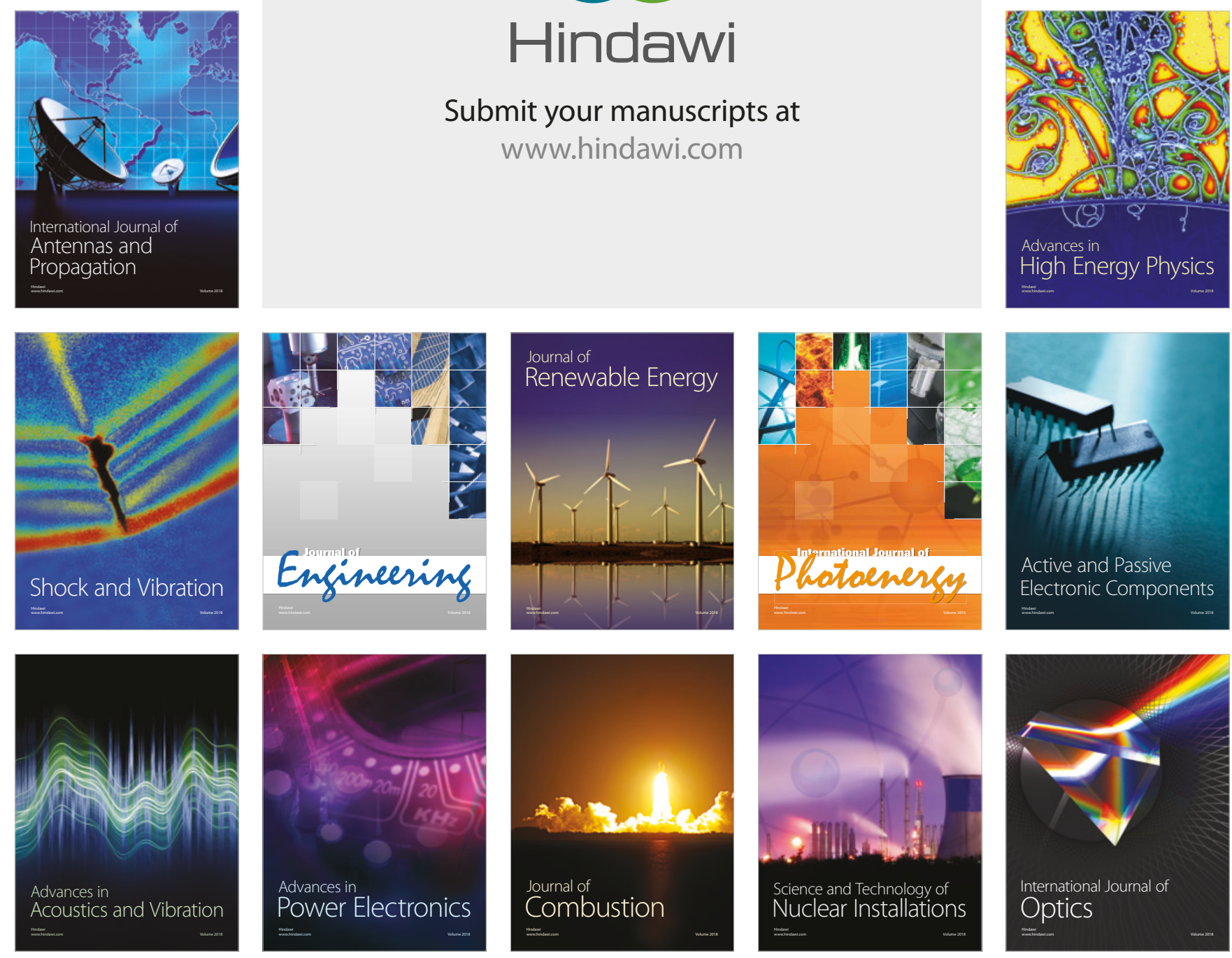